\title{
Association of school performance indicators with implementation of the Healthy Kids, Smart Kids programme: case study
}

Tonja R Nansel ${ }^{1}$, Terry TK Huang ${ }^{1}$, Alisha J Rovner ${ }^{1}$ and Yvonne Sanders-Butler ${ }^{2, *}$

${ }^{1}$ Eunice Kennedy Shriver National Institute of Child Health and Human Development, National Institutes of Health, Department of Health and Human Services, Bethesda, MD, USA: ${ }^{2}$ Browns Mill Elementary School, Lithonia, GA, USA

Submitted 24 June 2008: Accepted 4 March 2009: First published online 19 May 2009

\begin{abstract}
Objective: The purpose of the present analysis was to examine secular trends in school performance indicators in relationship to the implementation of a programme targeting the school food and physical activity environment.

Design: Data on available school performance indicators were obtained; retrospective analyses were conducted to assess trends in indicators in association with programme implementation; each outcome was regressed $v$. year, beginning with the year prior to programme implementation.

Setting: The Healthy Kids, Smart Kids programme, a grass-roots effort to enhance the school food and physical activity environment in the Browns Mill Elementary School in Georgia.

Subjects: Data included publicly available school records from the years 1995 to 2006.

Results: The number of nurse, counselling and disciplinary referrals per 100 students demonstrated a downward trend, while standardized test scores demonstrated an upward trend beginning in the year of programme implementation. School year was a significant predictor of all indicators.

Conclusions: Promoting nutrition and physical activity within the school environment may be a promising approach for enhancing both student health and educational outcomes.
\end{abstract}

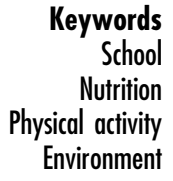

Poor dietary intake among US children is well established $^{(1-3)}$, contributing to a dramatic increase in the prevalence of overweight ${ }^{(4)}$. Childhood overweight contributes to depressed affect, low self-esteem and social marginalization $^{(5)}$; increases risk for obesity in adulthood $^{(6)}$; and increases risk for adult chronic disease ${ }^{(7)}$. Even for nonoverweight children, poor diet increases the risk for chronic disease (e.g. references 8 and 9). Poor diet and physical inactivity account for an estimated 365000 deaths per annum, second only to tobacco in preventable deaths ${ }^{(10)}$, and result in an estimated \$US 110-129 billion annually in direct and indirect health-care costs ${ }^{(11)}$.

Because US children consume from 19 to $50 \%$ of their daily energy intake at school ${ }^{(12)}$, the school environment is an important target for improving dietary intake. A body of research clearly indicates that the school food environment impacts children's diets. Vending machines, snack bars and à la carte programmes in schools have been associated with lower consumption of fruits and vegetables, and higher consumption of total fat, saturated fat and sweetened beverages ${ }^{(13-15)}$.
Multi-component school-based intervention studies involving educational, environmental and parent components have shown increases in fruit consumption ranging from $0 \cdot 2$ to 0.6 servings/d and increases in vegetable consumption ranging from 0 to $0 \cdot 3$ servings $/ \mathrm{d}^{(16)}$. While the educational components of these studies were generally the primary focus, several have documented positive changes in the nutritional content of school meals $^{(17-19)}$. Only a few studies have specifically examined the effect of modifying the school food environment on children's dietary intake; findings suggest the potential effectiveness of such changes ${ }^{(20-22)}$. Additionally, school policy and procedure changes have resulted in measurable improvements in children's diets and health ${ }^{(23-25)}$.

Despite evidence indicating the importance of the school food environment, findings from the 2007 School Nutrition Dietary Assessment Study indicate that the nutritional composition of school meals is not optimal ${ }^{(26)}$. Less than one-third of public schools served lunches meeting the US Department of Agriculture standards for total or saturated fat. Essentially all meals exceeded the 
Na recommendations, and only about $5 \%$ of lunch menus contained foods made from whole grains or dried beans. Moreover, less healthy foods that competed with the school lunch foods remained prevalent. Approximately one-third of elementary schools and almost two-thirds of middle and high schools had foods or beverages for sale à la carte during lunch, with candy, desserts, snack foods, soda and juice drinks the most commonly purchased of these competitive foods.

While data indicate a need for improvement in the school food environment, significant barriers to such change exist. Qualitative research indicates that school personnel perceive that competitive foods are an important source of revenue, that food offerings should include both healthy and unhealthy foods to help students learn to make choices, and that academic achievement is the top priority among many competing demands, such as the healthfulness of foods served ${ }^{(27)}$.

There is an urgent need to determine ways in which the school food environment can be improved in a manner acceptable to school personnel and children and sustainable in terms of cost and effort. Further, evidence is needed to show the effects of changes in the school environment on health and school performance-related outcomes. The purpose of the present paper is to describe the development and implementation of the Healthy Kids, Smart Kids programme and the trajectory of school performance indicators observed over time prior to and after the implementation of this programme. These retrospective analyses do not constitute a formal evaluation of the programme; rather, they examine secular trends of publicly available school indicators before and after programme implementation.

\section{Methods}

Development of the Healthy Kids, Smart Kids programme was initiated in the Browns Mill Elementary School in Decatur, Georgia (a suburb of Atlanta) in 1999 in response to the school principal's concerns regarding an increase in obesity, high numbers of visits to the school nurse for general complaints, perceived lethargy in many students, and lack of focus and attention in the classroom. Using a community-based grass-roots approach, the principal formed a nutrition team consisting of the cafeteria manager, three teachers, three parents, the head custodian, a bus driver, two members of student government, two members of the $4 \mathrm{H} \mathrm{Club}$, and several neighbourhood grocery store managers. The team reviewed the school menus and made recommendations for improvements; changes were made within the existing budgetary constraints of the school's food service programme. Additionally, changes were made to the physical education curriculum and health-oriented topics were integrated into the regular school curriculum across subjects. Parental support for the initiative was facilitated
Table 1 School environment improvements in the Healthy Kids, Smart Kids programme

Food environment

1. Food items that were high in added sugar, saturated fat and salt were eliminated from the school menus

2. More fresh vegetables, salads, fruits and nuts were added to the school menu and the vending machines

3. High-fibre wholegrain cereal and bread items were added to the school menus

4. Only water, $100 \%$ fruit juices and low-fat milk were available at the school (including vending machines)

5. Menus were designed to support students and staff members with special dietary needs, such as those with diabetes, high blood pressure and high cholesterol

6. School policy that all foods brought from home to school (e.g. packed lunches) had to be in compliance with the healthy meal guidelines*. Cookies, chips, cakes, candy and sodas were restricted on the school campus

7. Classroom parties were required to follow the healthy meal guidelines*

Physical activity

1. Students engaged in $40 \mathrm{~min}$ (ages 4 to 8 years) to $60 \mathrm{~min}$ (ages 9 to 12 years) of physical activity each school day as part of daily school activities

2. A weekly circuit training course was implemented throughout the school year, consisting of stations such as jump rope, push-ups, sit-ups, dance and step aerobics

3. Pedometers were distributed and physical activity diaries were completed by 5 th grade children

4. Aerobics, strength training and walking classes were offered to staff in the gym before and after school hours, and a personal trainer conducted classes twice a day 3 times a week

\section{Curriculum changes}

1. Topics related to healthy eating were integrated into crosscurricular study. Materials were developed that were incorporated into math, science, language, arts and social studies classes and provided links to the school food service and physical education activities

2. Classroom-based materials based on social cognitive theory were prepared. The materials were designed to enhance cognitive and behavioural skills for developing a healthy lifestyle to enable students to make changes in their own behaviour, develop skills that strengthen perceived competence in employing new behaviours effectively, and provide support for these behaviours

*Based on the 1995 Dietary Guidelines for Americans ${ }^{(32)}$ and the Food Guide Pyramid (now replaced by MyPyramid).

through a series of parent-teacher-student association meetings, workshops, staff developments and in-services to discuss health and nutrition issues, including education regarding guidelines for food brought to school from home. A key emphasis of the approach was to integrate the programme into existing school structures and curricula via an interdisciplinary approach. A summary of the school environment changes implemented is provided as Table 1, and sample menus prior to and after programme implementation are provided as Table 2. A programme steering committee including representatives from the school council, the parent-teacher-student association, the student government and the community was formed to guide programme development and implementation, and the subsequent school environment changes occurred over approximately one year. 
Table 2 Sample school menus prior to and after the implementation of Healthy Kids, Smart Kids programme

\begin{tabular}{|c|c|c|}
\hline & Prior to Healthy Kids, Smart Kids & After Healthy Kids, Smart Kids \\
\hline Monday & $\begin{array}{l}\text { Cheese pizza } \\
\text { Chicken nuggets } \\
\text { Corn } \\
\text { Garden salad } \\
\text { Peaches } \\
\text { Cookies }\end{array}$ & $\begin{array}{l}\text { Tuna salad } \\
\text { Veggie pizza on wholegrain crust } \\
\text { Green salad } \\
\text { Carrot \& celery sticks (low-fat Ranch dressing) } \\
\text { Fresh fruit cup } \\
\text { Yoghurt }\end{array}$ \\
\hline Tuesday & $\begin{array}{l}\text { Hamburger } \\
\text { Corn dog } \\
\text { Green beans } \\
\text { French fries } \\
\text { Fruit cocktail } \\
\text { Graham crackers }\end{array}$ & $\begin{array}{l}\text { Baked roasted chicken } \\
\text { Turkey sub sandwich on wholegrain bread } \\
\text { Turnip greens } \\
\text { Baked sweet potato } \\
\text { Spinach salad } \\
\text { Fresh fruit (seasonal) }\end{array}$ \\
\hline Wednesday & $\begin{array}{l}\text { Beef/cheese taco } \\
\text { Burrito/cheese } \\
\text { Tomato/lettuce } \\
\text { Mixed vegetables } \\
\text { Fruit } \\
\text { Banana pudding }\end{array}$ & $\begin{array}{l}\text { Spaghetti with turkey meat sauce } \\
\text { Grilled chicken breast } \\
\text { Wheat rolls } \\
\text { Mixed vegetables } \\
\text { Green beans } \\
\text { Stewed pears } \\
\text { Fresh fruit }\end{array}$ \\
\hline Thursday & $\begin{array}{l}\text { Chicken rings } \\
\text { Breaded steak } \\
\text { Buttered rice } \\
\text { Garden salad } \\
\text { Cookie bar } \\
\text { Fruit }\end{array}$ & $\begin{array}{l}\text { Turkey pot pie } \\
\text { Meat loaf } \\
\text { Baked white potato } \\
\text { Broccoli } \\
\text { Garden salad } \\
\text { Fresh fruit (seasonal) } \\
\text { Apple sauce }\end{array}$ \\
\hline Friday & $\begin{array}{l}\text { Hot dog } \\
\text { Burritos } \\
\text { Coleslaw } \\
\text { French fries } \\
\text { Cherry crisp }\end{array}$ & $\begin{array}{l}\text { Chef salad (salad mix with spinach, tomatoes, bell peppers, } \\
\text { cucumbers, garbanzo beans, turkey and turkey ham, } \\
\text { low-fat cheddar cheese) } \\
\text { Loaded baked potato (turkey chilli, broccoli, low-fat cheddar } \\
\text { cheese, low-fat sour cream) } \\
\text { Wholegrain roll } \\
\text { Fresh fruit } \\
\text { Italian organic ice }\end{array}$ \\
\hline Items available all days & $\begin{array}{l}\text { Whole milk } \\
\text { Chocolate milk } \\
\text { Sweetened juice drink } \\
\text { Ice cream (cups, bars) } \\
\text { Popsicles }\end{array}$ & $\begin{array}{l}\text { Low-fat milk ( } 1 \% \text { and } 2 \%) \\
\text { Skimmed milk } \\
\text { Soya milk } \\
\text { Bottled water } \\
100 \% \text { juice (apple/fruit blend) }\end{array}$ \\
\hline
\end{tabular}

While the Healthy Kids, Smart Kids programme was not implemented as part of a research study, publicly available school records were used to examine trends in school indicators relative to the timing of the programme implementation, which began in 1999. School indicator data available prior to programme development included the Iowa Test of Basic Skills (ITBS) and data on the number of disciplinary referrals. The ITBS is a nationally standardized, norm-referenced test for students from first to eighth grade, designed to assess performance in relation to the national population. Beginning the year prior to programme implementation (1998), data on the number of nurse and counselling referrals were also kept. Trends in these indicators in association with implementation of the Healthy Kids, Smart Kids programme were examined using regression analyses. Each outcome was regressed $v$. year, beginning with the year prior to programme implementation through until 2006. (ITBS data were used only until 2005 , as the standardized testing format was changed in 2006, precluding comparison with previous years.) Data analyses were conducted using the SPSS statistical software package version $13 \cdot 0$ (SPSS Inc., Chicago, IL, USA).

\section{Results}

A summary of the school demographic characteristics across the years analysed is provided in Table 3. The school primarily served African-American students. Approximately one-third to one-half of students were eligible for free or reduced-price lunches through the National School Lunch Program.

The number of nurse, counselling and disciplinary referrals per 100 students demonstrated a downward trend beginning in the year of programme implementation (Fig. 1). A slight increase was then observed in all indicators in 2003, followed by a continued decrease. 
Table 3 Demographic characteristics of students in Browns Mills Elementary School

\begin{tabular}{lccc}
\hline Year & $\begin{array}{c}\text { Number of students } \\
\text { enrolled in school }\end{array}$ & $\begin{array}{c}\text { \% Eligible for the National } \\
\text { School Lunch Program }\end{array}$ & \% African-American \\
\hline 1995 & 1005 & $34 \cdot 9$ & $87 \cdot 8$ \\
1996 & 1026 & $37 \cdot 9$ & $87 \cdot 6$ \\
1997 & 834 & $36 \cdot 9$ & $92 \cdot 0$ \\
1998 & 779 & $50 \cdot 0$ & $93 \cdot 3$ \\
1999 & 875 & $41 \cdot 4$ & $95 \cdot 1$ \\
2000 & 945 & $43 \cdot 7$ & $95 \cdot 4$ \\
2001 & 950 & $43 \cdot 2$ & $95 \cdot 6$ \\
2002 & 1049 & $51 \cdot 2$ & $96 \cdot 0$ \\
2003 & 945 & $49 \cdot 0$ & $97 \cdot 0$ \\
2004 & 1002 & $53 \cdot 0$ & $96 \cdot 0$ \\
2005 & 1002 & $54 \cdot 0$ & $96 \cdot 0$ \\
2006 & 1050 & $55 \cdot 0$ & $96 \cdot 0$ \\
\hline
\end{tabular}

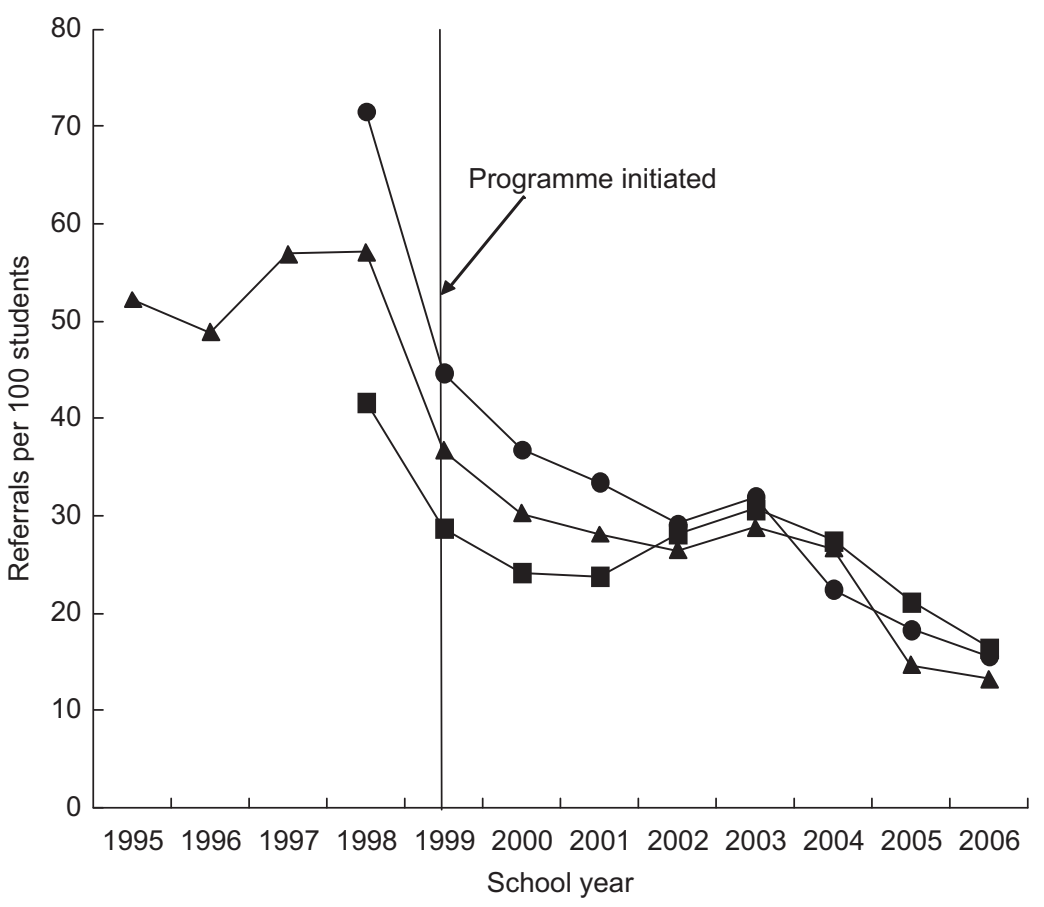

Fig. 1 Number of nurse $(\bullet)$, counselling $(\boldsymbol{\square})$ and disciplinary $(\boldsymbol{\Lambda})$ referrals by school year: Healthy Kids, Smart Kids programme. School year as a predictor of number of referrals: nurse referrals, $R^{2}=0.81, B=-0.90, P=0.001$; counselling referrals, $R^{2}=0.51, B=-0.71, P=0.03$; disciplinary referrals, $R^{2}=0.85, B=-0.92, P<0.001$

School year was a significant predictor of number of referrals (nurse referrals: $R^{2}=0 \cdot 81, P=0 \cdot 001$; counselling referrals: $R^{2}=0.51, P=0.03$; disciplinary referrals: $R^{2}=$ 0.85, $P<0 \cdot 001)$. Conversely, standardized test scores demonstrated an upward trend beginning in the year of programme implementation (Fig. 2), and school year significantly predicted test scores $\left(R^{2}=0 \cdot 49, P=0 \cdot 02\right)$.

\section{Discussion}

Findings from the current retrospective analysis suggest that promoting nutrition and physical activity within the school environment may be complementary to educational needs. Previous research has demonstrated the relationship of undernourishment to cognition and behaviour ${ }^{(28,29)}$; however, little research has addressed the relationship of dietary quality with these factors. A notable exception is a recent epidemiological study in Nova Scotia, which found that greater overall dietary quality was associated with better performance on a standardized reading assessment after adjusting for weight status, parent/family characteristics and neighbourhood demographic factors ${ }^{(30)}$.

While the current analysis was not designed to formally evaluate the programme, and improvements in school indicators cannot be causally attributed, secular trends in school indicators associated with programme implementation suggest it may be a promising approach for promoting both health and educational outcomes. The success of the 


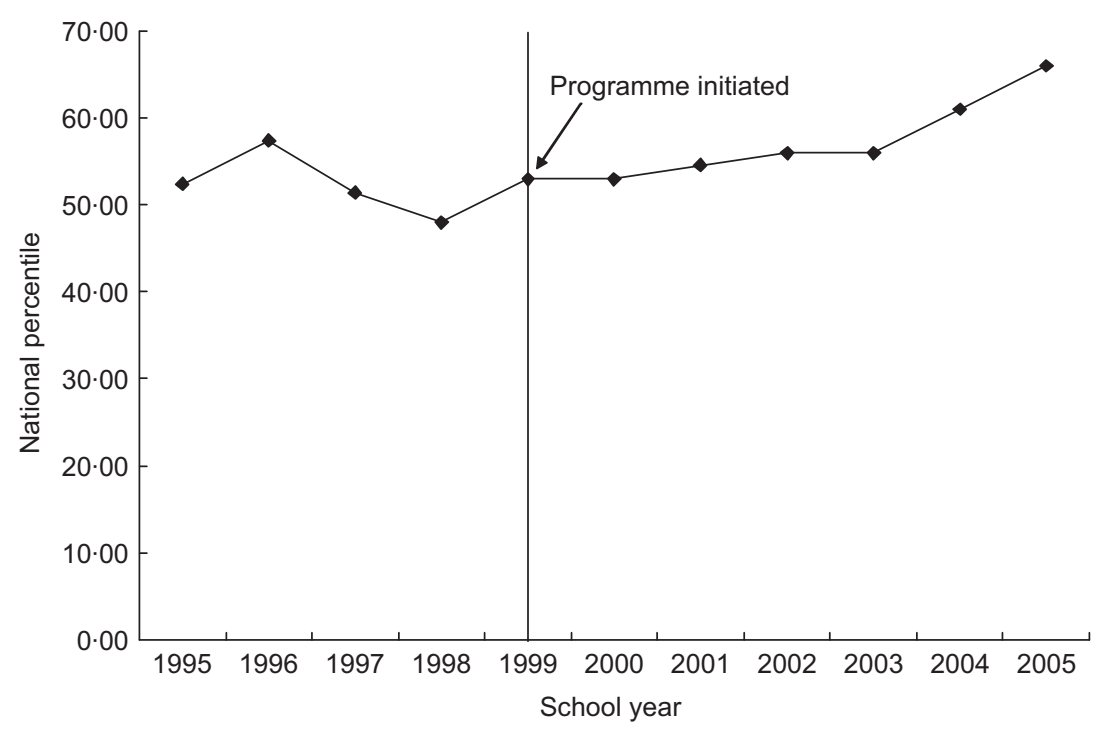

Fig. 2 Standardized reading test scores by school year: Healthy Kids, Smart Kids programme. School year as a predictor of reading test percentile: $R^{2}=0 \cdot 49, B=0 \cdot 70, P=0.02$

programme in achieving food and physical activity changes in the school environment suggests the potential effectiveness of a grass-roots approach. Such change must overcome a number of barriers, including changes in the way food is purchased, prepared and served; acceptability of the new menus by students; competing priorities of school personnel; prioritizing time for physical activity during the school day; and social attitudes normalizing unhealthy foods. As a result, achieving successful environmental change requires a strong champion and achieving buy-in from diverse stakeholders. In this case, the success of the project was facilitated by a highly motivated principal with strong leadership skills, who was willing to share her own personal story of wellness as an initial step towards gaining trust and interest from staff, students and parents. Members of the transdisciplinary team, who demonstrated substantial commitment to the recommended changes, were empowered to make the decisions needed to ensure the success of the programme. For example, the cafeteria manager communicated with vendors to obtain healthful foods, developed cafeteria promotions of new food items, and arranged for local sports mascots to visit the school to educate students about the importance of eating healthily. While formal data on the acceptability of the programme among students and parents were not obtained, feedback was solicited through anonymous 'How Are We Doing Healthy Watch' boxes placed in high-traffic areas throughout the school and during registration; school staff report that about $90 \%$ of the feedback received was positive. The successful implementation of the Healthy Kids, Smart Kids programme highlights the utility of a community-based participatory approach and the importance of developing and sustaining effective relationships between the principal, other school administrators and staff, teachers, parents and children.
In 2004, the Child Nutrition and WIC Reauthorization Act required that local school districts develop a wellness policy by 2006, setting goals for nutrition education, physical activity and food provisions to address the epidemic of childhood obesity. Due to inconsistent responses by school districts, Congress directed the Centers for Disease Control and Prevention to undertake a study with the Institute of Medicine to review and make recommendations about appropriate nutritional standards for the availability, sale and content of foods at school. Their report, Nutrition Standards for Foods in Schools: Leading the Way toward Healthier Youth $^{(31)}$, concluded that: (i) federally reimbursable school nutrition programmes should be the main source of nutrition at school; (ii) opportunities for competitive foods should be limited; and (iii) if competitive foods are available, they should consist of nutrient-dense foods including fruits, vegetables, whole grains and non-fat or low-fat milk and dairy products, consistent with the 2005 Dietary Guidelines for Americans ${ }^{(32)}$. The Healthy Kids, Smart Kids programme is consistent with these recommendations, and could serve as a feasible and sustainable model for the development of other schools' wellness policies.

To our knowledge, no study on nutrition- and fitnessrelated programmes in schools has addressed the impact on school factors such as disciplinary referrals, nurse referrals, counselling referrals or test scores. Findings from the present analysis suggest the relevance of examining these outcomes in future school-based nutrition interventions. If prospective research indicates that healthful dietary change in the school facilitates achievement and social development outcomes, such findings would provide compelling support for further development and dissemination of such programmes.

As the Healthy Kids, Smart Kids programme was not implemented as part of a research study, there was no 
attempt to assess individual-level data or control for possible historical factors, and formal comparison data are not available. As such, it is not possible to determine the extent to which the observed positive trends are associated with the programme. However, retrospective inquiry as to possible historical factors that may account for the findings yielded no major changes in educational approaches or other school-related factors. Importantly, there was an increase in the percentage of students eligible for free or reduced-price school lunches, indicating a decrease in socio-economic status across the years studied. As such, the observed improvements in school performance indicators are especially remarkable. In 2002, all schools were mandated to implement a mentoring programme for students in single-parent homes and foster care. The increase in counselling referrals from 2001 to 2002 is believed to be attributable to this mandate. Additional limitations, due to the retrospective nature of the analyses, include the lack of data on actual dietary intake, students' BMI and costs of programme implementation (although no external funding was provided for this programme), as well as specific data on acceptability of the programme among students, parents and staff.

As one of the first schools to eliminate highly processed foods and substitute more nutritious options, Browns Mill Elementary School serves as an example of a successful grass-roots effort to improve the healthfulness of the school environment with regard to food choices and physical activity. While other local grass-roots efforts are occasionally reported in the media and other sources, little or no evaluation of such efforts has occurred. Findings from the current retrospective analysis suggest that such an approach is promising. While the primary motivator for implementing programmes such as the one described here is to impact student physical health, these efforts may improve school performance indicators as well.

\section{Acknowledgements}

This project received no external funding. Data analysis and manuscript preparation were supported by the Intramural Research Program of the National Institutes of Health, Eunice Kennedy Shriver National Institute of Child Health and Human Development. The contents of this publication do not necessarily represent the views or policies of the National Institutes of Health. None of the authors possesses any conflicts of interest. Y.S.-B. led the development and implementation of the Health Kids, Smart Kids programme and obtained the school data reported. T.R.N., A.J.R. and T.T.K.H. conceptualized the retrospective data analysis. T.R.N. conducted analyses and drafted the manuscript; all author contributed to critical revisions. Y.S.-B. wishes to acknowledge the contribution of the following individuals to the success of the Healthy Kids, Smart Kids programme. Marilyn
Hughes, PhD, RD, LD (nutrition research scientist) assisted with the development of the Healthy Kids, Smart Kids Programme. Lorine Phillips Bizzell (public health nutritionist) analysed recipes and provided technical assistance and resources for the Healthy Kids, Smart Kids Programme. James L. Lawrence (fitness specialist) supported the physical activity format that promoted health and exercise throughout the school day.

\section{References}

1. Guenther PM, Dodd KW, Reedy J \& Krebs-Smith SM (2006) Most Americans eat much less than recommended amounts of fruits and vegetables. J Am Diet Assoc 106, 1371-1379.

2. Munoz KA, Krebs-Smith SM, Ballard-Barbash R \& Cleveland LE (1997) Food intakes of US children and adolescents compared with recommendations. Pediatrics 100, 323-329.

3. Subar AF, Krebs-Smith SM, Cook A \& Kahle LL (1998) Dietary sources of nutrients among US children, 1989-1991. Pediatrics 102, 913-923.

4. Ogden CL, Carrol MD, Curtin LR, McDowell MA, Tabak CJ \& Flegal KM (2006) Prevalence of overweight and obesity in the United States, 1999-2004. JAMA 295, 1549-1555.

5. Puhl RM \& Latner JD (2007) Stigma, obesity, and the health of the nation's children. Psychol Bull 133, 557-580.

6. Singh AS, Mulder C, Twisk JW, van Mechelen W \& Chinapaw MJ (2008) Tracking of childhood overweight into adulthood: a systematic review of the literature. Obes $\operatorname{Rev}$ 9, 474-488.

7. Li S, Chen W, Srinivasan SR, Bond MG, Tang R, Urbina EM \& Berenson GS (2003) Childhood cardiovascular risk factors and carotid vascular changes in adulthood: the Bogalusa Heart Study. JAMA 290, 2271-2276.

8. Frankel S, Gunnell DJ, Peters TJ, Maynard M \& Smith GD (1998) Childhood energy intake and adult mortality from cancer: the Boyd Orr cohort study. BMJ 316, 499-504.

9. Maynard M, Gunnell D, Emmett P, Frankel S \& Davey SG (2003) Fruit, vegetables, and antioxidants in childhood and risk of adult cancer: the Boyd Orr cohort. J Epidemiol Community Health 57, 218-225.

10. Mokdad AH, Marks JS, Stroup DF \& Gerberding JL (2005) Correction: actual causes of death in the United States, 2000. JAMA 293, 293-294.

11. US Department of Health and Human Services (2001) The Surgeon General's Call to Action to Prevent and Decrease Overweight and Obesity. Rockville, MD: Public Health Service, Office of the Surgeon General.

12. Gleason P \& Suitor C, US Food and Nutrition Service (2001) Children's Diets in the Mid-1990s: Dietary Intake and Its Relationship with School Meal Participation. CN-01-CD1. Alexandria, VA: US Department of Agriculture, Food and Nutrition Service.

13. Cullen KW \& Zakeri I (2004) Fruits, vegetables, milk, and sweetened beverages consumption and access to a la carte/ snack bar meals at school. Am J Public Health 94, 463-467.

14. Kubik MY, Lytle LA, Hannan PJ, Perry CL \& Story M (2003) The association of the school food environment with dietary behaviors of young adolescents. Am J Public Health 93, 1168-1173.

15. Neumark-Sztainer D, French SA, Hannan PJ, Story M \& Fulkerson JA (2005) School lunch and snacking patterns among high school students: associations with school food environment and policies. Int J Behav Nutr Phys Act 2, 14.

16. French SA \& Wechsler H (2004) School-based research and initiatives: fruit and vegetable environment, policy, and pricing workshop. Prev Med 39, Suppl. 2, S101-S107. 
17. Cunningham-Sabo L, Snyder MP, Anliker J, Thompson J, Weber JL, Thomas O, Ring K, Stewart D, Platero H \& Nielsen L (2003) Impact of the Pathways food service intervention on breakfast served in American-Indian schools. Prev Med 37, 6 Pt 2, S46-S54.

18. Osganian SK, Ebzery MK, Montgomery DH et al. (1996) Changes in the nutrition content of school lunches: results from the CATCH Eat Smart food service intervention. Prev Med 25, 400-412.

19. Story M, Snyder MP, Anliker J, Weber JL, Cunningham-Sabo L, Stone EJ, Chamberlain A, Ethelbah B, Suchindran C \& Ring K (2003) Changes in the nutrient content of school lunches: results from the Pathways study. Prev Med 37, 6 Pt 2, S35-S45.

20. Eriksen K, Haraldsdottir J, Pederson R \& Flyger H (2003) Effect of a fruit and vegetable subscription in Danish schools. Public Health Nutr 6, 57-63.

21. French SA, Story M, Fulkerson JA \& Hannan P (2004) An environmental intervention to promote lower-fat food choices in secondary schools: outcomes of the TACOS study. Am J Public Health 94, 1507-1512.

22. Schwartz MB (2007) The influence of a verbal prompt on school lunch fruit consumption: a pilot study. Int J Behav Nutr Phys Act 4, 6.

23. Cullen KW, Watson K \& Zakeri I (2008) Improvements in middle school student dietary intake after implementation of the Texas public school nutrition policy. Am J Public Health 98, 111-117.

24. Ellison RC, Capper AL, Goldberg RJ, Witschi JC \& Stare FJ (1989) The environmental component: changing school food service to promote cardiovascular health. Health Educ Q 16, 285-297.

25. Foster GD, Sherman S, Borradaile KE, Grundy KM, Vander Veur SS, Nachmani J, Karpyn A, Kumanyika S \& Shults J (2008) A policy-based school intervention to prevent overweight and obesity. Pediatrics 121, e794-e802.

26. Gordon A \& Fox MK (2007) School Nutrition Dietary Assessment Study III. Summary of Findings. Alexandria, VA: US Department of Agriculture, Food and Nutrition Service, Office of Research, Nutrition and Analysis.

27. Nollen NL, Befort CA, Snow P, Daley CM, Ellerbeck EF \& Ahluwalia JS (2007) The school food environment and adolescent obesity: qualitative insights from high school principals and food service personnel. Int J Behav Nutr Phys Act 4, 18.

28. Kretchmer N, Beard JL \& Carlson S (1996) The role of nutrition in the development of normal cognition. $\mathrm{Am} \mathrm{J}$ Clin Nutr 63, Suppl. 1, 997-1001.

29. Taras H (2003) Nutrition and student performance at school. J Sch Health 75, 199-213.

30. Florence MD, Asbridge M \& Veugelers PJ (2008) Diet quality and academic performance. J Sch Health $\mathbf{7 8}$, 209-215.

31. Institute of Medicine (2007) Nutrition Standards for Foods in Schools: Leading the Way toward Healthier Youth. Washington, DC: Institute of Medicine of the National Academies.

32. US Department of Health and Human Services \& US Department of Agriculture (1995) Dietary Guidelines for Americans 1995. Washington, DC: US Government Printing Office. 